\title{
DEVELOPMENT OF STEFAN-BOLTZMANN BOARD GAME BASED ON GAME CHARACTERISTICS
}

\author{
Ary Norsaputra ${ }^{1}$, Thasaneeya Ratanaroutai Nopparatjamjomras ${ }^{1}$, Suchai \\ Nopparatjamjomras ${ }^{1}$ and Ratchapak Chitaree ${ }^{2}$ \\ ${ }^{1}$ Institute for Innovative Learning, Mahidol University, Thailand \\ ${ }^{2}$ Departement of Physics, Faculty of Science, Mahidol University, Thailand
}

\begin{abstract}
The purposes of this study are to develop Stefan-Boltzmann board game and evaluate the components (main board, metal hexagon, self-card, information card, and action card) based on five game characteristics which are competition and goals, strategy and tactical, challenges, rules, and fantasy elements. The topics covered by this board game are Stefan-Boltzmann's law, radiation power emitted by object, absolute temperature, area, and emissivity. The game characteristics of the board game were assessed by a Physics lecturer and a game expert via a set of 5-point Likert scale assessment tool during the implementation of the board game. The participants were four Indonesian students who had a bachelor degree from faculty of Education and were taking a one year course for the professional physics teacher certification. The score of 'main board' for each game characteristics are $3.5,3.5,4,5$, and 4.5 respectively to competition and goals, game choices, challenges, rules, and game fantasy. In addition, a semi-structured interview was used to collect students' opinion on game characteristics that will be used to improve the board game in the future.
\end{abstract}

Keywords: Stefan-Boltzmann's law, board game, game characteristics

\section{Introduction}

In 1895, modern physics was started with the unsolved questions related to the phenomena of the blackbody radiation (Thorton and Rex, 2006). This issue is important and has been taught in modern physics class at undergraduate level (Siegel and Howell, 1972). Theoretically, "Blackbody" is an object which can absorb all of the incident electromagnetic radiation and releases those radiation, this phenomenon is called "Blackbody radiation", when the object is in thermal equilibrium. The power of radiation (P) emitted by an object of area (A) is directly proportional to the fourth power of the absolute temperature ( $T$ ) of the body as described by Stefan-Boltzmann law.

$$
P=\sigma A T^{4}
$$

Where $\sigma=5.67 \times 10^{-8} \mathrm{~W} / \mathrm{m}^{2} \mathrm{~K}^{4}$, is the Stefan-Boltzmann constant..

Many techniques to teach this topic have been developed by many researchers (Edmonds, 1968; Carvalho and Sousa, 2006; Lopresto and Hagoort, 2011; Marr and Wilkin, 2012; Sadoglu, 2015) and they revealed that students who had been taught via tradition teaching have many misconceptions such as students describe color as representative of the object temperature (Carvalho and Sousa, 2006), students always describe the blackbody as an object that has a dark color (Sadoglu, 2015).

Board game was recommended as a good educational tool (Smyrnaiouet al. 2012), which had a variety of descriptions such as 1) board game was a voluntary activity by players, using the rules, the specific time and place (Huizinga, 1938); 2) board game was the simple model that could make the complex system and difficult issues being the simple plain game processes (Bochenneket al. 2007); and 3) board game could present the newness in order for enhancing the curricula, more fun, and may touch each other (Allery, 2014).

The aims of our paper are 1) to develop the Stefan-Boltzmann board game; 2) to evaluate the board game components (Main board, Metal hexagon, Self-card, Information card, and Action card) in terms of game

Corresponding Author: SuchaiNopparatjamjomras/suchai.nop@mahidol.edu

$3^{\text {rd }}$ International Conference on Education, 20-22 2017, Kualalumpur, Malaysia 
characteristics (Competition and goals, Strategy and tactical, Challenge, Rules, and Fantasy) and students' attitude towards the game components.

\section{Literature Review}

Several studies have been approved that using board game as a learning tool has many positive effects to students such as 1) having potential to cover an element of competition and to motivate the students (Livingston and Stoll, C.S., 1973; Gershenand Handelman, 1974); 2) promoting an active learning (Richardson and Birge, 1995); 3) increasing students' communication skills by the game layout (Richardson and Birge, 1995); 4) making learning with joy (Allesi andTrolip, 2001); 5) repeating the steps of learning in each game turn (Bochenneket al. 2007); 6) replacing the simple memorization with an active learning and application concepts (Shiroma et al. 2011); and 7) promoting participation among peers (Popil and Dillard-Thompson, 2015).

A number of the board game have also been developed for teaching Physics e.g. "Voyager" (Smith, 2003) was used to improve students' knowledge about satellites, "Space Hunter" (Kirikayaet al.2010) was used to evaluate students' recognizing level of celestial object in the space and universe, and "Quantum race" was specially designed to bring the analogy fundamental quantum mechanical concept (Chiarello, 2015). However, there has been no board game related to Stefan-Boltzmann, so researchers would like to create the Stefan-Boltzmann board game.

\section{Stefan-Boltzmann Board Game}

The Stefan-Boltzmann board game was designed to cover the topics of Stefan-Boltzmann's law, radiation power emitted by object, absolute temperature, area, and emissivity. As Bochennek, K., Wittekindt, B., Zimmermann, S. Y., and Klingebiel, T. (2007) suggested that the combination of the board contents and rules would provide narrative, physical, and simulation aspect, the topics of Stefan-Boltzmann's law and radiation power emitted by object were embedded into the rules and mission of the Stefan-Boltzmann board game, respectively. The rules of the game have been set to show the concept of Stefan-Boltzmann's law, and the mission of the game is collecting the radiation power placed on the "Metal hexagon". In gathering the radiation power, player had to mark the temperature, area, and emissivity so they would notice that these parameters were affected to the radiation power emitted by an object.

On the other hand, this board game was also developed according to five game characteristics suggested by Charsky(2010). The game components consist of Main board, Metal hexagon, Self-card, Information card, and Action card (see Figure 1). The design of the "Main board" was in accordance with the scientific concept. The main information of the learning concept such as value of temperature, area, emissivity, and radiation power were contained in "Information card" and "Self-card". "Action card" was composed of a command to support the player to understand the Stefan-Boltzmann's laws e.g. The players were commanded to add more temperature on the "Main board" to increase the radiation power level. Lastly, "Metal Hexagon" was the color states located on the "Main board" to present the radiation power level by its color. On the other hand, "Metal hexagon" was used to place the radiation power which should be collected by players. 


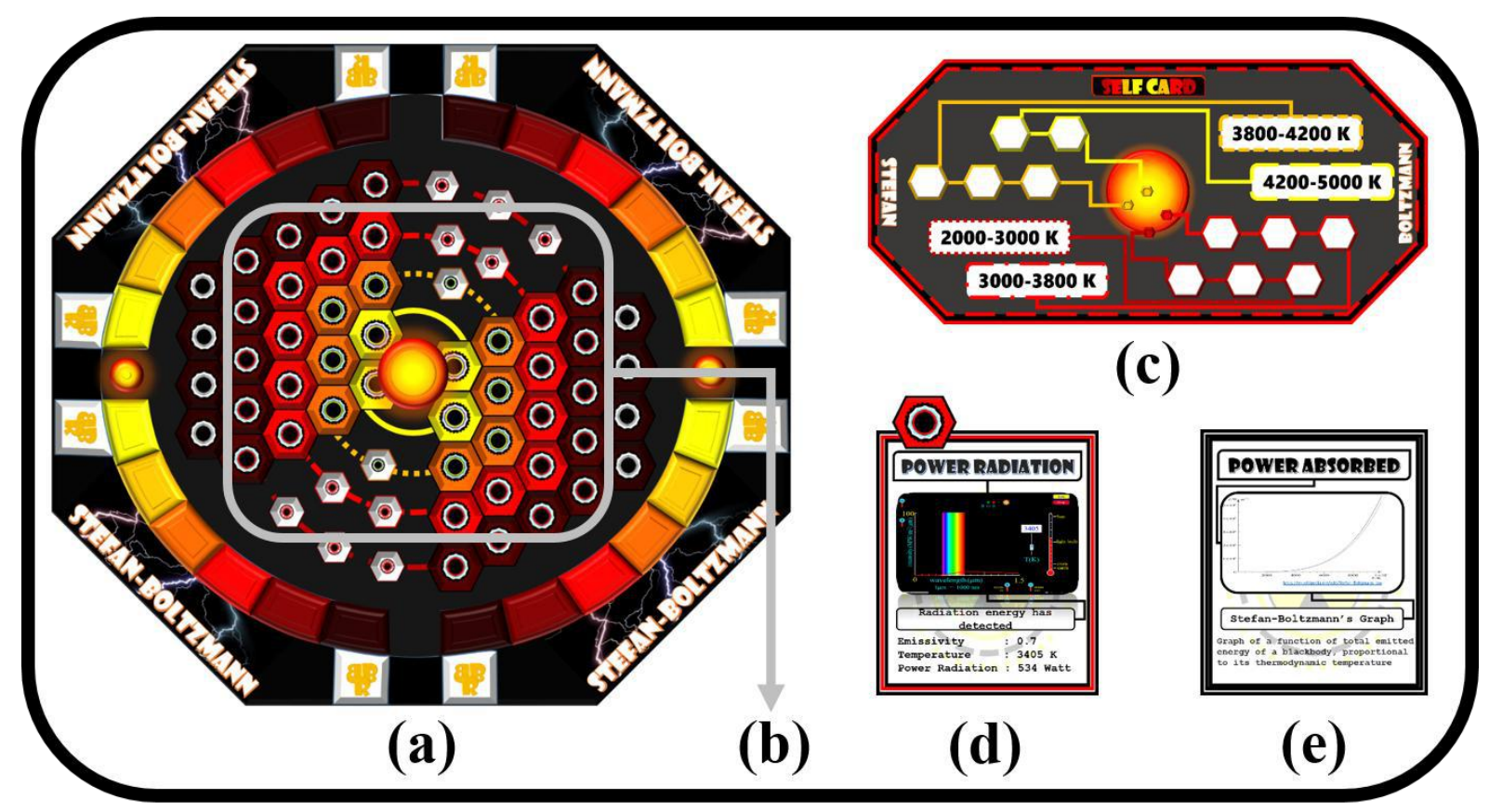

Figure 1 The Stefan-Boltzmann board game consists of (a) Main board, (b) Metal hexagon, (c) Self-card, (d) Information card, and (e) Action card.

\section{Methods}

To assess the Stefan-Boltzmann board game components, the research instruments, which were consisting of an assessment sheets and a semi-structured interview, were developed by researchers. This was a part of the main research which was approved by institutional review board at Institute of Population and Social Research (IPSRIRB), Mahidol University.

The Likert-scale assessment sheet, which was developed regarding to five game characteristics (Charsky, 2010), was used by the experts to assess the game components. The semi-structured interview and the voice recorder were used to collect students' attitude towards the game. The voice recording was analyzed through a thematic approach which was transcribed verbatim, grouped based on similarities as open coding (Corbin and Strauss, 1990), and interpreting.

The Stefan-Boltzmann board game was implemented with 4 participants who were taking professional physics teacher program. The implementation was started with the introduction of the game components and the game rules. The participants had 40 minutes to play the game. During this time the experts assessed the quality of the board game components via the assessment sheet. After the game was finished, all participants were interviewed in Bahasa by one of researchers.

\section{Findings}

\section{The Stefan-Boltzmann board game component}

The game components (Main board, Metal hexagon, Self-card, Information card, and Action card) were assessed by the experts toward five game characteristics; Competition and goals, Strategy and tactical, Challenge, Rules, and Fantasy. The results are shown in the Table 1.

Each component had dominant score at several game characteristics. The "Main board" and "Metal hexagon" had the high score at the characteristics of "Rules" and "Fantasy" and the low score for "Competition and 
goals". This meant that the "Main board" and "Metal hexagon" had the good rules (based on the contents of Stefan Boltzmann's law and radiation power emitted by object) that could lead the player to get into game fantasy. In addition, the score for "Strategy and tactical" of "Metal hexagon" was higher than those of "Main board". This could refer that the board game need more components than only "Main board" to give students a chance to use strategy and tactic. This interpretation was also supported by the score of "Self-card" and "Information card" for Strategy and tactical". However, the Stefan-Boltzmann board game could challenge students as it reflects from the "Challenge" score.

On the other hand, the "Self-card" and "Information card" had the high score for four game characteristics which are "Strategy and tactical", "Challenge", "Rules", and "Fantasy". However, both cards had the low score for "Competition and goals". This results were agreed with the function of these cards; giving the physics contents to the players. In fact, if students read the contents on both cards, they could be able to plan some strategies and tactics to face the challenges of the game. In addition, the combination of "Self-card" and "Information card" could make the game more fantasy.

As the "Action card" was designed to frame students to learn some concepts and support both "Self-card" and "Information card" in fulfilling their action roles, the combination of these three cards should enhance all game characteristics except rules. However, the scores of "Action card" were low for all game characteristics. In addition, the game components had a low score for "Competition and goals".

Table 1 The average score of Stefan-Boltzmann board game components

\begin{tabular}{lccccc}
\hline \multirow{2}{*}{$\begin{array}{l}\text { came } \\
\text { Main board }\end{array}$} & \multicolumn{5}{c}{ Average score of game characteristics } \\
\cline { 2 - 6 } & Competition and goals & Strategy and tactical & Challenge & Rules & Fantasy \\
\hline Metal hexagon & 3.5 & 3.5 & 4 & 5 & 4.5 \\
\hline Self-card & 3 & 4 & 4 & 4.5 & 4.5 \\
\hline Information card & 3 & 5 & 4.5 & 5 & 4.5 \\
\hline Action card & 3.5 & 4.5 & 5 & 4.5 & 4.5 \\
\hline *scale interpretation $1=$ Very poor, 2 = Poor, 3 = Acceptable, $4=$ Good, $5=$ Very Good &
\end{tabular}

\section{Students'attitude towards the game components}

As seen in Table 1, the score for "Competition and goals" was very low for all game components. This could be confirmed by the interview of the player \#3; his/her focus was avoiding stuck at "black object" ("blackbody swath" on the main board) rather than compete in the game. This was because he/she would be lost his/her Metal hexagon (a representative of radiation power; the winner of this game is the one who collect the most Metal hexagon), if he/she stuck at blackbody swath. This lost made he/she feel disadvantaged so he/she assumed that the competition was not real competition. This matter causing the given score by experts were low. However, this situation did not happen to all players such as Player \#2.

\begin{tabular}{ll}
\hline Player \#1 & $\ldots$..umm"... \\
Player \#2 & $\ldots$ "yes, we compete in this game"... \\
Player \#3 & $\ldots$ "Then, for the competition is not a real competition, because the opportunity to fall at the \\
& black object more often than the chance to win"... \\
Player \#4 & $\ldots$.."umm"...
\end{tabular}

As explain in the previous subtopic that the Stefan-Boltzmann board game could challenge students, this could be confirmed by the responses of Player \#1 and Player \#2 below. Especially, the "Information card" (Power radiation card) made Player \#1 feel very challenge to collect the card. 


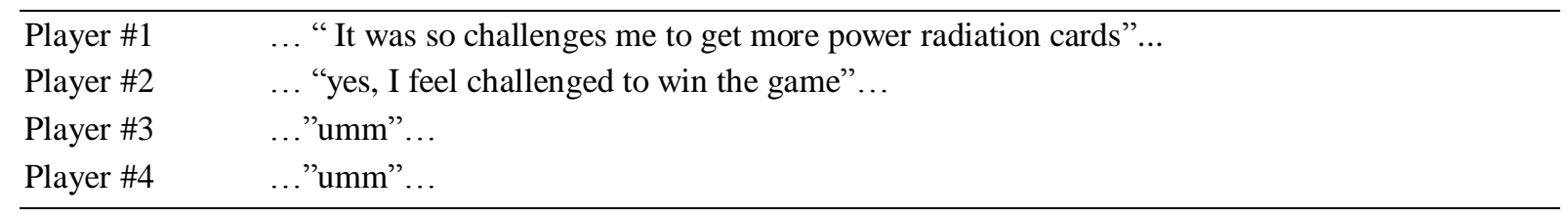

For the characteristic of "Rules", many game components had the high score. This meant that many game components were guided by the clearly rules. For example, the rules for "Main board" were to control the players to 1) move their game avatar 2) use the "Information card" and "Action card", and 3) collect the radiation power from "Metal hexagon". This could help the players to run the game easily but some of them (Player \#4) thought the rules were not show the game purpose which is learning the concept of StefanBoltzmann's law.

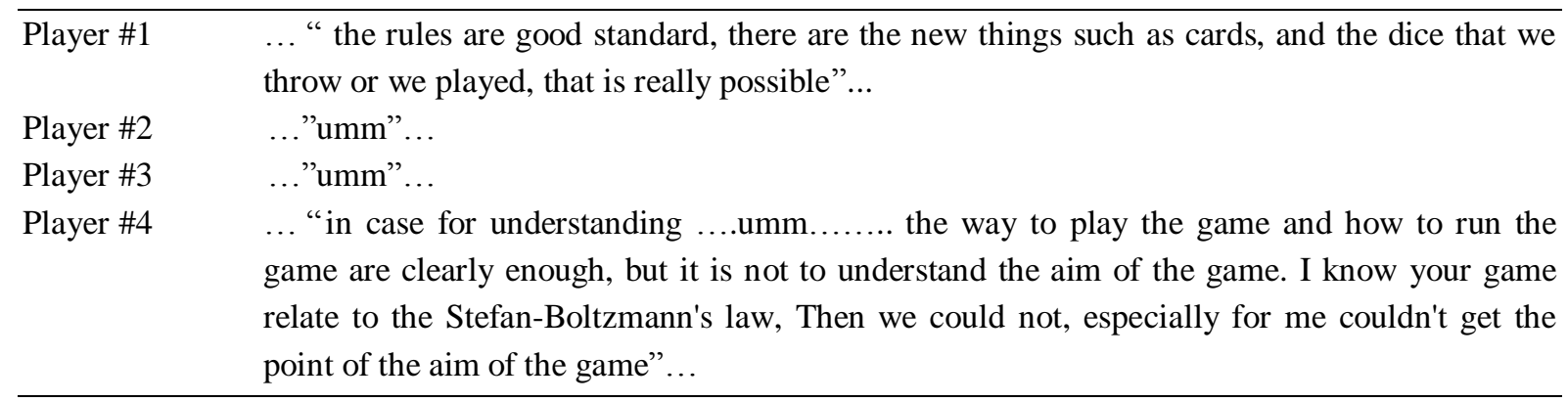

As interpreted in the previous subtopic, the "Self-card" and "Information card" were designed to present the concept of Stefan-Boltzmann's Law. This information should be faced by players while they got it and may let the players having good understanding towards the concepts. This might be the explanation why the score of "Challenge" for both were higher than those of others (see Table 1). It was approved by Player \#1's response that he/she could differentiate the radiation power level by temperature; the yellow color had the highest temperatures (in the range of dark red to yellow). In addition, students could use the information from these cards to create their strategic plan that was approved by Player \#2 and Player \#4. They mentioned that if they understood the contents on the information cards, they should collect the metal hexagon in order of its energy level (highest to lowest). This feature was in accordance with Malone and Lepper(1987). On the other side, the "Main board" and "Metal hexagon" also offered the good strategy by their challenge e.g. if the players noticed that it was not necessary to complete all parameters to obtain the radiation power, they could cheat with acquiring opponents' parameters with completing the last parameters in the same value to radiation power.

\begin{tabular}{ll}
\hline Player \#1 & $\ldots$ "Yellow has the highest temperature, because it is the brightest"... \\
Player \#2 & $\ldots$ "As I remember, it showed. Because, yellow color emitted by the glowing object have the \\
& highest temperature than another color. I think the radiation power also higher than others"... \\
Player \#3 & .. "umm.......At first, I was not, because I did not pay attention to self-card but after half the \\
& game, I noticed it in directions in color and there is already listed"... \\
Player \#4 & $\begin{array}{l}\text {.. "For the theory, any way we can occasion. We're Getting the card, then we have time to } \\
\text { read, so and we had the most good right strategy at yellow, orange and it is its higher-energy } \\
\end{array}$ \\
& radiation"...
\end{tabular}

In addition, the Player \#1 and Player \#2 were able to determine the temperature of incandescent object by its color.

\section{Discussion and Conclusion}


The concepts of radiation power emitted by object, absolute temperature, area, and emissivity were integrated into a game cycle as the Stefan-Boltzmann board game. This game could present the interaction among the concepts in an enthusiastic way.

The components of this board game, which were Main board, Metal hexagon, Self-card, Information card, and Action card, were evaluated by the experts based on game characteristics: Competition and goals, Strategy and tactical, Challenge, Rules, and Fantasy.

All game components except "Action card" were good at all game characteristics except "Competition and goals". This could be explained as 1) the students were not familiar with the game; 2) the researcher did not have enough time to explain each game components and game rules, clearly; 3) the level of challenge for each game components were not the same that made the goals of the game unclear; and 4) the Stefan-Boltzmann board game was designed for a single purpose (to cover the topics of Stefan-Boltzmann's law, radiation power emitted by object, absolute temperature, area, and emissivity) whereas Eisenack(2013) suggested that the good game design should serve multiple purposes. On the other hand, the explanation for low score of "Action card" was the insufficient implementation time for players to have a chance to use the card. This was because the "Action card" was not distributed to students at the starting of the game, students had to collect the card during the game. These results will be used to develop the other version of the Stefan-Boltzmann board game.

However, this learning approach could encourage students to read the information of the Self-cards and Information cards that could help students to understand the Stefan-Boltzmann's law. Especially the effect of the absolute temperature to the radiation power emitted or absorbed by the object. This was in accordance with the statement proposed by Chiarello(2015) as "board games can be useful supports for the exposition and explanation of complex scientific concepts".

\section{Acknowledgement}

This study was conducted under the Grant of Mahidol-Norway Capacity Building Initiative for ASEAN. We also wish to thank the Faculty of Graduate Studies of Mahidol University which support the financial cost in attending the $3^{\text {rd }}$ International Conference on Education (ICEDU) 2017 in Kuala Lumpur, Malaysia. Also the experts; Ms. Shelly Effwinda and Mr. AgusRiyadi, and all other people involved in the research.

\section{References}

Alessi, S.M. and Trollip, S.R., 2000. Multimedia for learning: Methods and development (Allyn \& Bacon, Inc).

Allery, L., 2014, Make use of educational games. Education for Primary Care, 25(1), 65-66.

Bochennek, K., Wittekindt, B., Zimmermann, S. Y., \&Klingebiel, T., 2007, More than mere games: a review of card and board games for medical education. Medical teacher, 29(9-10), 941-948.

Carvalho, P. S., \& e Sousa, A. S., 2006, Should we use colours as symbolic representations of hot and cold?.Physics education, 41(3), 263-266.

Charsky, D., 2010, From edutainment to serious games: A change in the use of game characteristics. Games and Culture, 5(2), 177-198.

Chiarello, F., 2015, Board Games to Learn Complex Scientific Concepts and the" Photonics Games" Competition. In European Conference on Games Based Learning. Academic Conferences International Limited. Italy, October, (p. 774). 
AryNorsaputra, ThasaneeyaRatanaroutaiNopparatjamjomras, SuchaiNopparatjamjomras and RatchapakChitaree/Development Of Stefan-Boltzmann Board Game Based On Game Characteristics

Corbin, J. M., \& Strauss, A., 1990, Grounded theory research: Procedures, canons, and evaluative criteria. Qualitative sociology, 13(1), 3-21.

Edmonds, I. R. (1968). Stephan-Boltzmann law in the laboratory. American Journal of Physics, 36(9), 845-846.

Eisenack, K., 2013, A climate change board game for interdisciplinary communication and education. Simulation \& Gaming, 44(2-3), 328-348.

Gershen, J. A., \&Handelman, S. L., 1974, Role-playing as an educational technique in dentistry. Journal of dental education, 38(8), 451-455.

Huizinga, J., 2003, Homo Ludens: A Study of the Play Element in Culture (London, U.K.: Routledge)

Kirikaya, E. B., Iseri, S., \&Vurkaya, G., 2010, A Board Game about Space and Solar System for Primary School Students. The Turkish online Journal of Education technology, 9(2), 1-13.

Livingston, S. A., \& Stoll, C. S., 1973, Simulation games, an introduction for the Social Studies teacher. Free Press.

LoPresto, M. C., \&Hagoort, N., 2011, Determining Planetary Temperatures with the StefanBoltzmann Law. The Physics Teacher, 49(2), 113-116.

Malone, T. W., \&Lepper, M. R., 1987, Making learning fun: A taxonomy of intrinsic motivations for learning. Aptitude, learning, and instruction, 3(1987), 223-253.

Marr, J. M., \& Wilkin, F. P., 2012, A better presentation of Planck's radiation law. American Journal of Physics, 80(5), 399-405.

Popil, I., \& Dillard-Thompson, D., 2015), A game-based strategy for the staff development of home health care nurses. The Journal of Continuing Education in Nursing, 46(5), 205-207.

Richardson, D., \&Birge, B., 1995, Teaching physiology by combined passive (pedagogical) and active (andragogical) methods. The American journal of physiology, 268(6 Pt 3), 66-74.

Sadoglu, G. P., 2015, Turkish Student's Perception about the Black Body Radiation, Photoelectric Effect and Compton Scattering Phenomena. Journal of Studies in Education, 5(3), 309-326.

Shiroma, P. R., Massa, A. A., \& Alarcon, R. D., 2011, Using game format to teach psychopharmacology to medical students. Medical teacher, 33(2), 156-160.

Siegel, R., \& Howell, J. R., 1972, Thermal Radiation Heat Transfer (New York U.S.A: McGraw Hill).

Smith, D. R., 2003, "Voyager" an Educational Card game. Physics Education, 38(1), 47-51.

Smyrnaiou, Z., Foteini, M., \&Kynigos, C., 2012, Students' constructionist game modelling activities as part of inquiry learning processes. Electronic Journal of E-Learning, 10(2), 235-248.

Thornton, S., \& Rex, A., 2006, Modern Physics for Scientists and Engineers fourth Edition (Cengage Learning). 